\title{
EFFECT OF 4\% ARTICAINE INFILTRATION VERSUS 2\% LIDOCAINE NERVE BLOCK AFTER PREMEDICATION BY IBUPROFEN ON ANESTHETIC EFFICACY IN ENDODONTIC TREATMENT OF ACUTE IRREVERSIBLE PULPITIS: A RANDOMIZED CLINICAL TRIAL (PART III)
}

\author{
Nesma Ali Shabaan*, Ghada ELHilaly Eid** and Geraldine Mohamed Ahmed**
}

\begin{abstract}
Objective: The aim of the present study was to assess effect of $4 \%$ articaine infiltration versus $2 \%$ lidocaine nerve block after premedication by ibuprofen on anesthetic efficacy in endodontic treatment of first mandibular permanent molar with acute irreversible pulpitis in a randomized clinical trial.
\end{abstract}

Subjects and Methods: Fifty-two patients actively experienced pain diagnosed to be irreversible pulpitis of a mandibular molar tooth accepted to participate in this single-blinded study and underwent single visit endodontic treatment. All patients were equally distributed in control and experimental group. Every patient received $4 \%$ artiacine as buccal infiltration or $2 \%$ lidocaine as inferior alveolar nerve block (IANB) after one hour from receiving ibuprofen $600 \mathrm{mg}$ as premedication. Endodontic access was initiated after 10 minutes of anesthesia, lip numbness and electric pulp tester (EPT) reading. Pain during endodontic access cavity preparation and cleaning and shaping was recorded by visual analogue scale (VAS). When patients needed, they received intra-pulpal anesthesia of the same anesthetic solution as supplemental. All the data were collected and tabulated. Statistical analysis was performed by Microsoft Office 2013 (Excel), the significant level was set at $\mathrm{P} \leq 0.05$. Statistical analysis was done by Chi square test for categorical data.

Results: There was no statistically significant difference between lidocaine group (42.3\%, $76.9 \%)$ and articaine group $(53.8 \%, 69.2 \%)$, in success of pain control during access cavity preparation and cleaning and shaping, respectively.

Conclusions: On the basis of the results of this study, it can be concluded that: The $4 \%$ articaine buccal infiltration and $2 \%$ lidocaine inferior alveolar nerve block have the same anesthetic efficacy in mandibular first molar with irreversible pulpitis after premedication with ibuprofen.

KEYWORDS: articaine, lidocaine, infiltration, inferior alveolar nerve block 


\section{INTRODUCTION}

Effective pain control in endodontics represents a hallmark of clinical excellence. The major cause of pain is thought to be due to the release of inflammatory mediators that activate sensitive nocioceptors surrounding the tooth ${ }^{1}$. Local anesthesia is primary method used to control pain during dental treatment, however a common clinical problem is the difficulty experienced in obtaining satisfactory anesthesia of acutely painful inflamed pulp ${ }^{2}$.

The inferior alveolar nerve block is the most frequently used mandibular injection technique for achieving local anesthesia for endodontic treatment. However, the inferior alveolar nerve block does not always result in successful pulpal anesthesia ${ }^{3,4}$. Lidocaine is the most frequently used local anesthetic solution in dentistry ${ }^{5}$. The clinicians seek alternative methods to improve the level of pain control of anesthesia using different techniques of local anesthesia administration as well as changing the type of local anesthetic agent.

Buccal infiltration is usually not preferred in the mandibular molar regions because the presence of dense cortical bone which impedes adequate diffusion of the anesthetic solution ${ }^{6}$. Even though, infiltration technique has lower incidence of failure than IANB, it is simple, less painful. A Report showed that the lidocaine was not the best anesthetic agent for buccal infiltration technique for mandibular molars ${ }^{7}$. Articaine is an amide local anesthetic that contains a thiophene ring and an additional ester ring instead of a benzene ring that is found in lidocaine. These rings might allow the molecule to diffuse more readily ${ }^{8}$. These features of articaine allow better diffusion through soft and hard tissues than other local anesthetics and make it a suitable choice for mandibular molars infiltaration?

The administration of non steroidal antiinflammatory drugs (NSAID) such as ibuprofen before anesthesia injection in endodontic treatment of patients with irreversible pulpitis may ensure the patient a comfortable experience by a profound anesthesia ${ }^{10,11}$. The aim of the present study was to assess effect of $4 \%$ articaine infiltration versus $2 \%$ lidocaine nerve block after premedication by ibuprofen on anesthetic efficacy in endodontic treatment of first mandibular permanent molar with acute irreversible pulpitis in a randomized clinical trial.

\section{SUBJECTS AND METHODS}

This study was designed as a randomized clinical trial and self funded. Trial design methodology conforms to the Consolidated Standard of Reporting Trials (CONSORT) statement. Fifty-two emergency patients with age range (18-45) were enrolled in the study. They were attending endodontic clinic, Faculty of Oral and Dental Medicine, Cairo University. All patients were in good health as determined by medical history. Patient's signs and symptoms gave tentative diagnosis of acute irreversible pulpitis in mandibular first molar tooth. Patients exhibited intermittent pain after thermal stimuli or spontaneous pain which was sharp or dull, diffuse or referred with no pain on biting or palpation or percussion. Periapical radiograph revealed no periapical involvement or presence of slight widening of periodontal ligament space. Patients who had any known sensitivity or adverse reactions to any of the administered drugs, articaine $\left(3 \mathrm{M}^{\mathrm{TM}}\right.$ ESPE ${ }^{\mathrm{TM}}$, Bracknell, United Kingdom), lidocaine (Safco Dental Supply Co., Buffalo, NY, United States) or ibuprofen (Abbott Laboratories, Illinois, USA), and those with clinically observed lesions or swellings at the injection site were excluded from the study.

In this study, visual analogue scale (VAS) was used to rate clinical pain intensity in diagnosis, access cavity, cleaning and shaping. The scale consists of a 10-cm line anchored by two extremes, "no pain" and "worst pain" felt. Patients were 
asked to make a mark on the line that represented their level of perceived pain. Thus, pain intensity was assigned into 4 categorical scores: score 1; none (0); score 2: mild (1-3); score 3: moderate (4-6); and score 4: severe $(7-10)^{12}$.

The degree of pulp sensitivity was detected by Electric pulp tester (Denjoy Dental CO., LTD, Changsha city, China).The pulp tester was used in two steps: diagnosis of pulpal condition and after 10 minutes of anesthetic administration. The experimental tooth and the contra lateral tooth were tested with the electric pulp tester to determine tooth sensitivity and obtain baseline information. The value at the initial sensation was recorded. The teeth were isolated with cotton rolls and dried with an air syringe. Tooth-paste was applied to the probe tip, which was placed on the tip of mesiobuccal cusp tip of the tooth being tested ${ }^{13}$.

After the procedures of the study were explained to the patients, they were asked to sign informed consent and were given a copy of it. Every patient was given one tablet of Ibuprofen $600 \mathrm{mg}$ (Abbott Laboratories, Illinois, USA) one hour before anesthesia. All local anesthetic injections were delivered by using a self-aspirating syringe and 27-gauge long needles. Regarding group A: patients were given standard IANB $2 \%$ lidocaine, while group B: patients were given mandibular infiltration injection by using a cartridge of $4 \%$ articaine. After 10 minutes ${ }^{14}$, the patient was questioned for lip and soft tissue numbness and the electric pulp tester reading was recorded.

Access cavity preparation was performed and patients were instructed to rate any discomfort (no or mild pain) on the VAS scale through preparation. If patient felt any pain (moderate or severe) during preparation this was recorded, then the subject was given supplemental intrapulpal anesthesia with the same anesthetic solution to effectively complete the procedure without pain.
After access cavity preparation the tooth was isolated with a rubber dam. Patients were instructed to rate any discomfort on the VAS scale during cleaning and shaping. If there was moderate or severe pain, VAS was recorded and patient would receive intrapulpal anesthesia as supplemental anesthesia with the same anesthetic solution. Determination of working length was done by the apex locator (Root ZX mini, J morita corporation ${ }^{\circledR}$, Suita City, Japan) and confirmed radiographically. Cleaning and shaping was done by rotary system using Revo-S ${ }^{\mathrm{TM}}$ files (Revo S, Micro-Mega ${ }^{\circledR}$, Besançon, France).

Success was defined as no or mild pain during access cavity or cleaning and shaping. All the data were collected and tabulated. Statistical analysis was performed by Microsoft Office 2013 (Excel). The significant level was set at $\mathrm{P} \leq 0.05$. Chi square test was used to compare between categorical data.

\section{RESULTS}

Regarding age: mean values were in lidocaine and articaine groups, 30.04 and 30.12; respectively, with no statistically significant difference between the two groups $(P=0.97)$.

Regarding sex: in lidocaine group, there were 9 males versus 17 females patients. While in articaine group, there were 10 males versus 16 females patients. There were no statistical significant difference between the two groups $(P=0.733)$.

\section{Frequency of scoring in each group, (Table 1)}

During access cavity: in lidocaine group the highest percentages of pain score was with severe pain $(42.3 \%, \mathrm{n}=11 / 26)$ patients followed by mild pain $(23.1 \%, 6 / 26)$, and no pain $(19.2 \%, 5 / 26)$ and the least was moderate pain $(15.4 \%, 4 / 26)$. While in articaine group the highest percentages of pain score was equally distributed between no and severe pain (each $38.5 \%, \mathrm{n}=10 / 26$ ), followed by mild pain $(15.4 \%, \mathrm{n}=4 / 26)$ and the least was moderate $(7.7 \%$, $\mathrm{n}=2 / 26)$. 
During Cleaning and shaping: in lidocaine group the highest percentages of pain score were with no and mild pain (each $38.5 \%, \mathrm{n}=10 / 26$ ) followed by moderate pain $(23.1 \%, n=6 / 26)$ and there was no severe pain. While in articaine group the highest percentages of pain score was with no pain $(42.3 \%$, $\mathrm{n}=11 / 26$ ), followed by mild and moderate pain (each $26.9 \%, \mathrm{n}=7 / 26$ ) and the least was severe pain $(3.8 \%, \mathrm{n}=1 / 26)$.

TABLE (1) Count and percentage of patients with no, mild, moderate or severe pain on VAS, during access cavity and cleaning and shaping after administering Lidocaine or Articaine

\begin{tabular}{|c|c|c|c|}
\hline \multicolumn{2}{|c|}{ Pain Quality } & $\begin{array}{c}\text { Lidocaine } \\
\text { Count (\%) }\end{array}$ & $\begin{array}{c}\text { Articaine } \\
\text { Count (\%) }\end{array}$ \\
\hline \multirow{4}{*}{$\begin{array}{c}\text { Access } \\
\text { cavity }\end{array}$} & No & $5(19.2)$ & $10(38.5)$ \\
\cline { 2 - 4 } & moderate & $4(15.4)$ & $2(7.7)$ \\
\cline { 2 - 4 } & severe & $11(42.3)$ & $10(38.5)$ \\
\hline \multirow{4}{*}{$\begin{array}{c}\text { Cleaning and } \\
\text { shaping }\end{array}$} & mo & $10(38.5)$ & $11(42.3)$ \\
\cline { 2 - 4 } & moderate & $6(23.1)$ & $7(26.9)$ \\
\cline { 2 - 4 } & severe & $0(0)$ & $1(3.8)$ \\
\hline
\end{tabular}

\section{Evaluation of Success of Anesthetic adminis- tration: (Figure 1)}

Access cavity: Percentages of successful cases were higher in articaine (53.8\%) compared to lidocaine $(46.1 \%)$, with no statistical significant difference between two groups, $P=0.405$.

Cleaning and shaping: Percentages of successful cases were higher in lidocaine (76.9\%) compared to articaine (69.2\%), with no statistical significant difference between 2 groups, $(P=0.532)$.

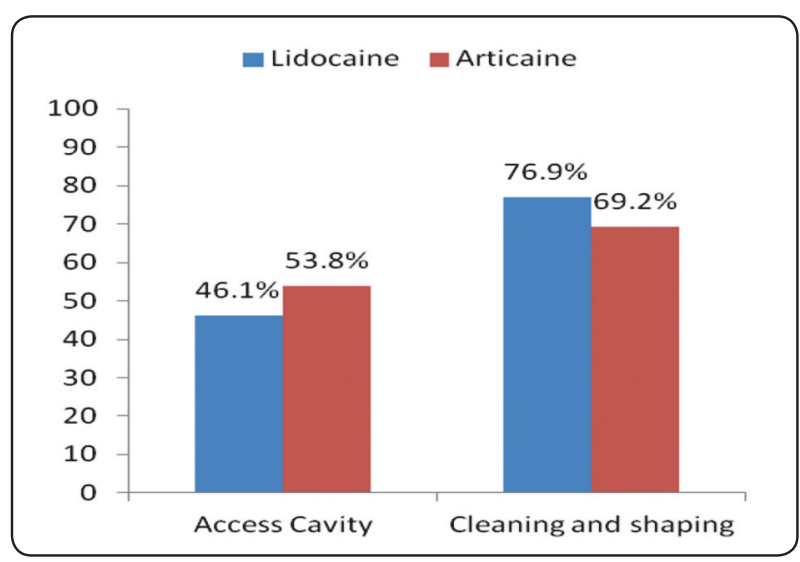

Fig. (1) Bar chart showing percentage of patients with successful pain control (with no, mild scores of VAS) during access cavity and cleaning and shaping after administering Lidocaine or Articaine

\section{DISCUSSION}

The purpose of this trial was to perform a comparative evaluation of efficacy of $4 \%$ articaine infiltration and 2\% lidocaine nerve block after premedication by NSAID such as ibuprofen. To the best of the authors Knowledge, there are no studies that compared articaine after premedication.

Inferior alveolar nerve block is the most frequent technique used with mandibular molars to achieve local anesthesia. However, it does not always result in successful pulpal anesthesia. Uncontrolled techniques or local anatomical variations are considered the main cause of IANB failure ${ }^{15}$. Lidocaine is the most local anesthetic used in dentistry. High efficacy, minimal allergy and safety of this drug made it the gold standard agent for IANB $^{16}$.

Buccal infiltration has a number of advantages that made it preferred over the IANB such as avoidance of the unwanted soft tissue anesthesia. Buccal infiltration is simple, less painful and the technique of choice for hemophilic patient ${ }^{7}$. However infiltration technique has some limitations in mandibular molars region. The presence of dense cortical bone limits the diffusion of many local anesthetic agents ${ }^{6}$. 
Articaine is an amide local anesthetic agent that contains a thiophene ring and additional ester ring, these rings allow the molecule to diffuse more readily ${ }^{8}$. This thiophene ring increased the lipid solubility of articaine which in turn determined the degree of molecules could penetrate nerve membranes ${ }^{5}$. These features of articaine allow better diffusion through soft and hard tissues; which is 1.5 times greater than lidocaine. Thus making it is a suitable choice for mandibular molars infiltaration? ${ }^{9}$

The premedication by non steroidal antiinflammatory drug used in the present study is based on the conclusion of the other studies ${ }^{10,11}$. It was found that premedication with NSAID improved the success rate of IANB ${ }^{10,11}$. Ibuprofen is still one of the most effective drugs for controlling dental pain, as it acts by blocking the COX pathways and decreasing the prostaglandin level ${ }^{17}$.

Determination of the pulpal ansthetic success has different methods as negative response to electric pulp tester and lip numbness. Previous studies $^{18,19}$ considered that the electric pulp tester alone is not always the reliable method to evaluate the pulpal anesthesia, but it is considered the most accurate method when the procedure can be done without pain. Tortamano et $a l^{20}$ reported that the lip numbness and soft-tissue anesthesia did not always guarantee successful pulpal anesthesia. Therefore, in the current study, the criteria of successful pulpal anesthesia was depended on the triad of soft tissue numbness, pulp tester and completing the access cavity with no or mild pain.

In the present study, patients who experienced moderate or severe pain, received supplemental intrapulpal anesthesia to complete the treatment painlessly. Walton and $\mathrm{Abbott}^{21}$, found that mandibular molars showed incomplete pulpal anesthesia and required more supplemental anesthesia than other types of teeth due to anatomical aberration such as the innervation of the mylohyoid nerve. This was in agreement with Monteiro et $a l^{18}$., who concluded that supplemental injections increased anaesthetic success rates.

According to the results of the current, successful cases were higher in articaine $(53.8 \%)$ than in lidocaine $(46.1 \%)$ during access cavity preparation, but with no statistical significant difference. This result was slightly similar to Mikesell et $a l^{6}$., who found that there was no significant difference between the articaine and lidocaine solutions (54\% and $48 \%$; respectively). On other hand, these results were contrary to Monteiro et $a l^{18}$., who found significant difference between articaine buccal infiltration and lidocaine IANB (40\% and 10\%; respectively). These differences might be attributed to the unequal number of patients in experimental groups; 30 patients in articaine group versus 20 ptients in lidocaine group. Furthermore, that study considered the criteria for their success to be totally pain free scoring after the primary injection or the need of only one supplemental injection during access cavity to eliminate pain.

During cleaning and shaping stage, successful cases were higher in lidocaine $(76.9 \%)$ than in articaine (69.2\%), with no significant difference. The slightly lower success of articaine can be due to the shorter duration of articaine buccal infiltration compared to lidocaine IANB, this suggestion was in agreement with El-Kholey et $a l^{22}$. The current study result was slightly similar to Poorni et $a l^{16}$, who found the success of articaine in buccal infiltration (65.4\%) and lidocaine in IANB (65.4\%) were the same, with no significant difference.

In the present study, the success rate of lidocaine during access cavity preparation (46.1\%) was slightly similar to that reported by Jung et $a l^{23}$ (43\%). Although Oleson et $a l^{24}$, used two cartridges of lidocaine and higher dose from premedication (800 mg), their result was slightly lower (41\%) than that of the present study. This discrepancy can be attributed to the usage of different pain scale. The reported success with lidocaine by Tortamano 
et $a l^{20}$, was higher $(70 \%)$ than that in the current study which may be due to their usage of higher volume of anesthetic solution compared to that in the present study.

Regarding, the success rate of lidocaine during cleaning and shaping, in the present study it was higher $(76.9 \%)$ than reported by Tortamano et $a^{20}$ and Poorni et $a l^{16}$., (45\% and $64.2 \%$; respectively). This might be related to the inclusion criteria that treated all mandibular molars with their anatomical variations and difficulties ${ }^{20}$. Also differences might be attributed to the absence of ibuprofen premedication in the study of poorni et $a l^{16}$.

In the present study, the success rate of articaine (53.8\%) during access cavity preparation was slightly similar to that reported with Jung et $a^{23}$., and Martin et $\mathrm{al}^{25}$., (54\% and 50\%; respectively). On the other hand, the articaine success rates that were reported by El-Kholy et $a l^{22}$., Corbett et $a l^{26}$., and Robertson et $a l^{27}$, respectively, were higher (56\%, 64.5\% and 87\%; respectively), than in the current study. This can be because El-Kholy et $a l^{22}$., depended on articaine for pain control during surgical extraction with additional lingual infiltration, while Corbett et $a l^{26}$., and Robertson et $a l^{27}$., investigated anaesthetization of healthy pulp rather than inflamed for anesthetic evaluation of articaine. Regarding cleaning and shaping, in the current study the success of articaine was slightly similar to that reported by Poorni et al ${ }^{16}$., (69.2\%, $65.4 \%$; respectively).

It should be taken into consideration that most of the literature evaluated success of anesthesia with different techniques, anesthetic agents at different stages during endodontic treatment and different scoring criteria for success that might cause the variability in results and inability for direct comparison. For that, there is a need for further standardized study design studies and trials for improving current research in pain control in symptomatic irreversible pulpitis.

\section{CONCLUSIONS}

On the basis of the results of this study, it can be concluded that: The $4 \%$ articaine buccal infiltration and $2 \%$ lidocaine inferior alveolar nerve block have the same anesthetic efficacy in mandibular first molar with irreversible pulpitis after premedication with ibuprofen.

\section{REFERENCES}

1. Potocnik I, Bajrovic F. Failure of inferior alveolar nerve block in endodontics. Endod Dent Traumatol 1999; 15(6):247-51.

2. Wallace JA, Michanowicz AE, Mundell RD, Wilson EG. A pilot study of the clinical problem of regionally anesthetizing the pulp of an acutely inflamed mandibular molar. Oral Surg Oral Med Oral Pathol 1985;59(5):517-21.

3. Bigby J, Reader A, Nusstein J, Beck M. Anesthetic efficacy of lidocaine/meperidine for inferior alveolar nerve blocks in patients with irreversible pulpitis. J Endod 2007; 33(1):7-10

4. Claffey E, Reader A, Nusstein J, Beck M, Weaver J. Anesthetic efficacy of articaine for inferior alveolar nerve blocks in patients with irreversible pulpitis. J Endod 2004;30(8):568-71.

5. Malamed SF. Handbook of local anesthesia, 4th ed. st. ed 1997. 63-4

6. Mikesell P, Nusstein J, Reader A, Beck M, Weaver J. A comparison of articaine and lidocaine for inferior alveolar nerve blocks. J Endod 2005;31(4):265-70.

7. Meechan JG. Infiltration anesthesia in the mandible. Dent Clin North Am 2010;54(4):621-9.

8. Malamed SF, Gagnon S, Leblanc D. Efficacy of articaine: a new amide local anesthetic. J Am Dent Assoc 2000;131(5):635-42.

9. Kanaa MD, Whitworth JM, Corbett IP, Meechan JG. Articaine and lidocaine mandibular buccal infiltration anesthesia: a prospective randomized double-blind crossover study. J Endod 2006;32(4):296-8.

10. Modaresi J, Dianat O, Mozayeni MA. The efficacy comparison of ibuprofen, acetaminophen-codeine, and placebo premedication therapy on the depth of anesthesia during treatment of inflamed teeth. Oral Surg Oral Med Oral Pathol Oral Radiol Endod 2006;102(3):399-403. 
11. Noguera-Gonzalez D, Cerda-Cristerna BI, ChavarriaBolanos D, Flores-Reyes H, Pozos-Guillen A. Efficacy of preoperative ibuprofen on the success of inferior alveolar nerve block in patients with symptomatic irreversible pulpitis: a randomized clinical trial. Int Endod J 2013;46(11):1056-62.

12. Jalalzadeh SM, Mamavi A, Shahriari S, Santos FA, Pochapski MT. Effect of pretreatment prednisolone on postendodontic pain: a double-blind parallel-randomized clinical trial. J Endod 2010;36(6):978-81.

13. Lin J, Chandler N, Purton D, Monteith B. Appropriate electrode placement site for electric pulp testing first molar teeth. J Endod. 2007 ;33. p 1296-8.

14. McEntire M, Nusstein J, Drum M, Reader A, Beck M. Anesthetic efficacy of $4 \%$ Articaine with 1:100,000 epinephrine versus 4\% articaine with 1:200,000 epinephrine as a primary buccal infiltration in the mandibular first molar. J Endod 2011;37(4):450-4.

15. Hargreaves KM, and Karl Keiser. Local anesthetic failure in endodontics. Endodontic Topics 2002;1(1). p 26-39.

16. Poorni S, Veniashok B, Senthilkumar AD, Indira R, Ramachandran S. Anesthetic efficacy of four percent articaine for pulpal anesthesia by using inferior alveolar nerve block and buccal infiltration techniques in patients with irreversible pulpitis: a prospective randomized double-blind clinical trial. J Endod 2011;37(12):1603-7.

17. Ferreira SH, Nakamura M, de Abreu Castro MS. The hyperalgesic effects of prostacyclin and prostaglandin E2. Prostaglandins 1978;16(1):31-7.

18. Monteiro MR, Groppo FC, Haiter-Neto F, Volpato MC, Almeida JF. $4 \%$ articaine buccal infiltration versus $2 \%$ lidocaine inferior alveolar nerve block for emergency root canal treatment in mandibular molars with irreversible pulpits: a randomized clinical study. Int Endod J 2015;48(2):145-52.
19. Sampaio RM, Carnaval TG, Lanfredi CB, Horliana AC, Rocha RG, Tortamano IP. Comparison of the anesthetic efficacy between bupivacaine and lidocaine in patients with irreversible pulpitis of mandibular molar. J Endod 2012;38(5):594-7.

20. Tortamano IP, Siviero M, Costa CG, Buscariolo IA, Armonia PL. A comparison of the anesthetic efficacy of articaine and lidocaine in patients with irreversible pulpitis J Endod 2009;35(2):165-8.

21. Walton RE, Abbott BJ. Periodontal ligament injection: a clinical evaluation. J Am Dent Assoc 1981;103(4):571-5.

22. El-Kholey KE. Infiltration anesthesia for extraction of the mandibular molars. J Oral Maxillofac Surg 2013; 71(10):1658.e1-5.

23. Jung IY, Kim JH, Kim ES, Lee CY, Lee SJ. An evaluation of buccal infiltrations and inferior alveolar nerve blocks in pulpal anesthesia for mandibular first molars. J Endod 2008;34(1):11-3.

24. Oleson M, Drum M, Reader A, Nusstein J, Beck M. Effect of preoperative ibuprofen on the success of the inferior alveolar nerve block in patients with irreversible pulpitis. $\mathrm{J}$ Endod 2010;36(3):379-82.

25. Martin M, Nusstein J, Drum M, Reader A, Beck M. Anesthetic efficacy of $1.8 \mathrm{~mL}$ versus $3.6 \mathrm{~mL}$ of $4 \%$ articaine with 1:100,000 epinephrine as a primary buccal infiltration of the mandibular first molar. J Endod. 2011;37(5):588-92.

26. Corbett IP, Kanaa MD, Whitworth JM, Meechan JG. Articaine infiltration for anesthesia of mandibular first molars. J Endod 2008;34(5):514-8.

27. Robertson D, Nusstein J, Reader A, Beck M, McCartney M. The anesthetic efficacy of articaine in buccal infiltration of mandibular posterior teeth. J Am Dent Assoc 2007;138(8):1104-12. 